\title{
Strategic Risk Management: Application to Manufacturing
}

\author{
D.J. Pons*
}

Department Mechanical Engineering, University of Canterbury, Christchurch, New Zealand

\begin{abstract}
Existing risk management methods have a tendency to be focussed on the threats (rather than the opportunities) and the technology risk (rather than the organisational features of the problem). Also, they are better developed for quantitative variables and where mathematically precise problem-representation exists than qualitative variables and where knowledge of the system behaviour is only subjective. They thus have limited applicability to the management of strategic risks at the organisational or sector level. This paper describes how risk management may be extended into risks other than technical, include the opportunities alongside the threats, and accommodate strategic issues. A system modelling method was used to develop a conceptual model for prophylactic risk management under these situations. The resulting model is of a conjectural nature but is a starting point towards a theory for strategic risk management. It also has implications for practitioners, demonstrated by application of the methodology to a case study. The specific case under examination is the manufacturing industry in New Zealand, and the methodology was applied to a representative manufacturing firm. The paper makes a methodological contribution in several ways. First, rather than concentrate on just the threats it identifies the opportunities and specific mechanisms by which they might be captured. The paper makes another contribution by developing a theoretical model for intersecting risk management with strategy formulation, in 'strategic risk management'. A third contribution is in the way the paper specifically addresses the risks faced by a manufacturing organisation. Within the limitations of the data available for this analysis, the results suggest that a strategy of outsourcing production to a lower wage country is not the only possible solution for a product-manufacturing firm. The fourth contribution is the provision not only of a theory, but also an integrated set of methods for use by practitioners. These methods are not prescriptive, but instead offer suggestions that can be adapted to various situations. A suggested project plan for deployment is also provided. Strategic management of manufacturing is otherwise somewhat ad-hoc and poorly integrated with risk management, and the model provides a method that could help organisations navigate the turbulence of the global economic manufacturing sector. While the methodology has been illustrated by application to the strategic risk in manufacturing organisations, it has the potential to be used in other situations in response to threats and opportunities that affect the long-term financial viability of the organisation.
\end{abstract}

Keywords: Risk management, strategy, manufacturing, system model, decision making, threat, opportunity.

\section{INTRODUCTION}

Risk management is important in many sectors, and the area under consideration in this paper is the manufacturing industry. This industry has particularly large risks due to the fluctuating patterns of global commerce. Regardless of the average global trends in manufacturing, there can be major threats (opportunities) that emerge at the national level, and these are not dispersed equally. Small countries are particularly sensitive as they do not have a large or diversified manufacturing base, and thus their governments seek to actively manage the risks. Large industrialised nations have different risks and likewise seek to avert threats and capture opportunity through active planning. Note that in this context 'risk' refers to both threat and opportunity. Thus strategic risk management becomes an important tool for these nations to manage the risks to the economic success of their manufacturing industries.

*Address correspondence to this author at the Department of Mechanical Engineering, University of Canterbury, Private Bag 4800, Christchurch 8020, New Zealand; Tel: +64-3-364 2987 Ext. 7214; Fax: +64-3-364 2078; E-mail: dirk.pons@canterbury.ac.nz

\section{BACKGROUND}

The risk management methodology provides processes for determining risk [1-3]. Risk is defined in the latest international risk-management standard ISO31000:2009 as the 'effect of uncertainty on objectives' [3] and specifically includes negative and positive outcomes, or what might more generally be termed threats and opportunities. Typical stages within risk-assessment are analysis, evaluation, and treatment. Various tools such as fault tree analysis (FTA) and failure mode effect analysis (FMEA) are available for use within the analysis stages.

Standard ISO31000 offers a way of thinking about risk, and a framework wherein other more specialised risk identification and treatment activities can be placed. However there are weaknesses in the methods, which makes them difficult to apply to the more strategic situations exemplified by the manufacturing case.

First, notwithstanding the standard's assertion that risk may be conceived as having negative or positive effects, the reality is that the practice of risk management has a tendency to be focussed on the threats rather than the opportunities. Second, the specialised analysis methods within the risk do- 
main are better developed for assessing the technology risk rather than the soft features of the problem. Thus the processes work well for root cause analysis for catastrophic hardware failure.

Third, the standard intends that risk-management be embedded throughout the organisation: that the methods '[provide] the basis for effective governance' (sec. A.3.3); that it be 'an integral part of ... strategic planning' (sec. 3b). However, the standard itself does not specifically identify the methods that practitioners might use for assessing risks of the strategic opportunity type, and thus does not give guidance in this matter. While there is guidance in the handbook [2] it is limited to SWOT analysis, and only a superficial mention without explanation. There is no reference in either document to the broader literature on strategy, or other methods that practitioners could use. Thus while the intent of the standard is to apply risk-management to strategic situations, the actual demonstrated integration is weak.

The management literature for strategy-setting already understands the idea of events being threat or opportunity, perhaps better than risk-management itself. For example, the Baldrige quality programme [4] has much to say that is relevant to strategy, perhaps more so than ISO31000 and HB436. However strategy-setting does not generally use the construct of risk being consequence-likelihood, nor the prioritisation by risk magnitude.

From a methodological and process perspective, the residual issue is the weak integration between riskmanagement and strategy-setting. Consequently, there is opportunity for risk-management to prove that it can add value to the strategic processes. The corollary is that there is opportunity for organisations to introduce risk-management constructs into their strategy-setting. In both cases there is a need to move beyond mere assertions of integration and show practitioners how this might be done, i.e. to develop the methodology.

This paper demonstrates a method to extend riskmanagement into strategic risks. It includes the opportunities alongside the threats, and demonstrates how risk management may be integrated into the strategic leadership for manufacturing organisations. The specific case under examination is the manufacturing industry in New Zealand.

\section{METHOD}

The need exists for a methodology for strategic risk management. The strategic elements are only mentioned in the existing standards [1] without detailing the mechanisms that might be used. Thus there is insufficient guidance to allow practitioners to apply risk management in strategic settings. The characteristics of strategy-setting that make it difficult to integrate with risk management are its qualitative variables and the high importance of capturing opportunities. The risk management methods recognise that risk incorporates both threat and opportunity, but are weighted towards the former and are weak at describing methods for going about capturing opportunities.

The present work adopted a system modelling approach to this problem. First, a conceptual model was developed for the risk management and strategy processes. This model necessarily accommodates qualitative variables, and is thus descriptive of the process rather than a simulation system. The model integrates both topics: risk management and strategy, and thereby provides a holistic treatment. Out of this model emerge some processes, and these are then applied to the specific case of manufacturing engineering.

System approaches have been successful in other domains for modelling the behaviour of complex systems. The basic approach is to decompose the complex system into components and describe the relationships between them in a structured manner, thereby providing a synthesis of the behaviour of the whole. The following modelling approach was used. The author refers to this as 'dynamic process analysis' (DPA) as it is designed to capture changeable effects under high uncertainty. The method is characterised by structured, deductive process that decomposes the process being analysed into multiple sub-activities (functions), and for each deduces initiating events, the controls that determine the extent of the outputs, the inputs required, the process mechanisms that are presumed to support the action, and the outputs. Activities may be further decomposed as necessary to depict the level of detail required. The resulting conceptual model is expressed graphically as a series of flowcharts using the integration definition zero (IDEF0) notation [5, 6].

The object types are inputs, controls, outputs, and mechanisms (ICOM), and are distinguished by placement relative to the box, with inputs always entering on the left, controls above, outputs on the right, and mechanisms below. The box itself describes a function (or activity), and the arc (line arrow) describes an object. In most other flowchart notations arrows represent sequence of activities. However, with the present notation it is important to note that arrows should be interpreted as conveying objects to activities (blocks). An activity may begin autonomously when its required inputs are available and its constraints permit. Consequently, the notation provides that multiple activity boxes can be simultaneously active, i.e. concurrent or parallel. Sequenced activities (series) can still be readily modelled where necessary.

The IDEF0 notation was selected in preference to any other form of flowchart as it has excellent ability to describe complex processes. In turn this stems at least partly from its explicit support for differentiating objects on the basis of type, a feature not readily supported by block diagrams and conventional flowcharts. Furthermore, it enforces a rigour (that can be lacking in other flowchart approaches) and this provides an element of built-in checking for consistency and error-checking.

\section{CONCEPTUAL MODEL FOR STRATEGIC RISK MANAGEMENT}

\subsection{Prophylactic Risk Management (MfR-1)}

The conceptual model is shown in Fig. (1) MfR-1. This is for the activity of prophylactic risk management, i.e. activities prior to any risk event occurring. The process starts with the definition of the scope (1) then the next activity is to identify root causes (2) of failure (or success). Next is to analyse risk (3) for each of these hazards to give consequence and likelihood of the event. The combination is risk. Then it is necessary to evaluate the risks (5), after which are 
activities to treat the risks (6) giving reduced consequences, likelihood or exposure to failure. In parallel is the activity of consulting affected stakeholders (7). This process is broadly consistent with the standard [1] although represented differently.

\subsection{Define the Scope of the Risk Analysis (MfR-1-1)}

The scope defines that which is included and excluded from the analysis. This is important because it constrains the subsequent decision-making. A proposed model for scope definition is shown in Fig. (2) MfR-1-1. The ultimate outcome, as per AS/NZS 4360, is to identify key characteristics for the project (1), and the criteria for tolerable risk that will be used in decision-making (2). The scope also depends on human behavioural effects. One is the strategic oversight (3), since risk assessment occurs within organisations which in turn are striving to meet strategic objectives as they respond to (or influence) their external environment. Another is indi-

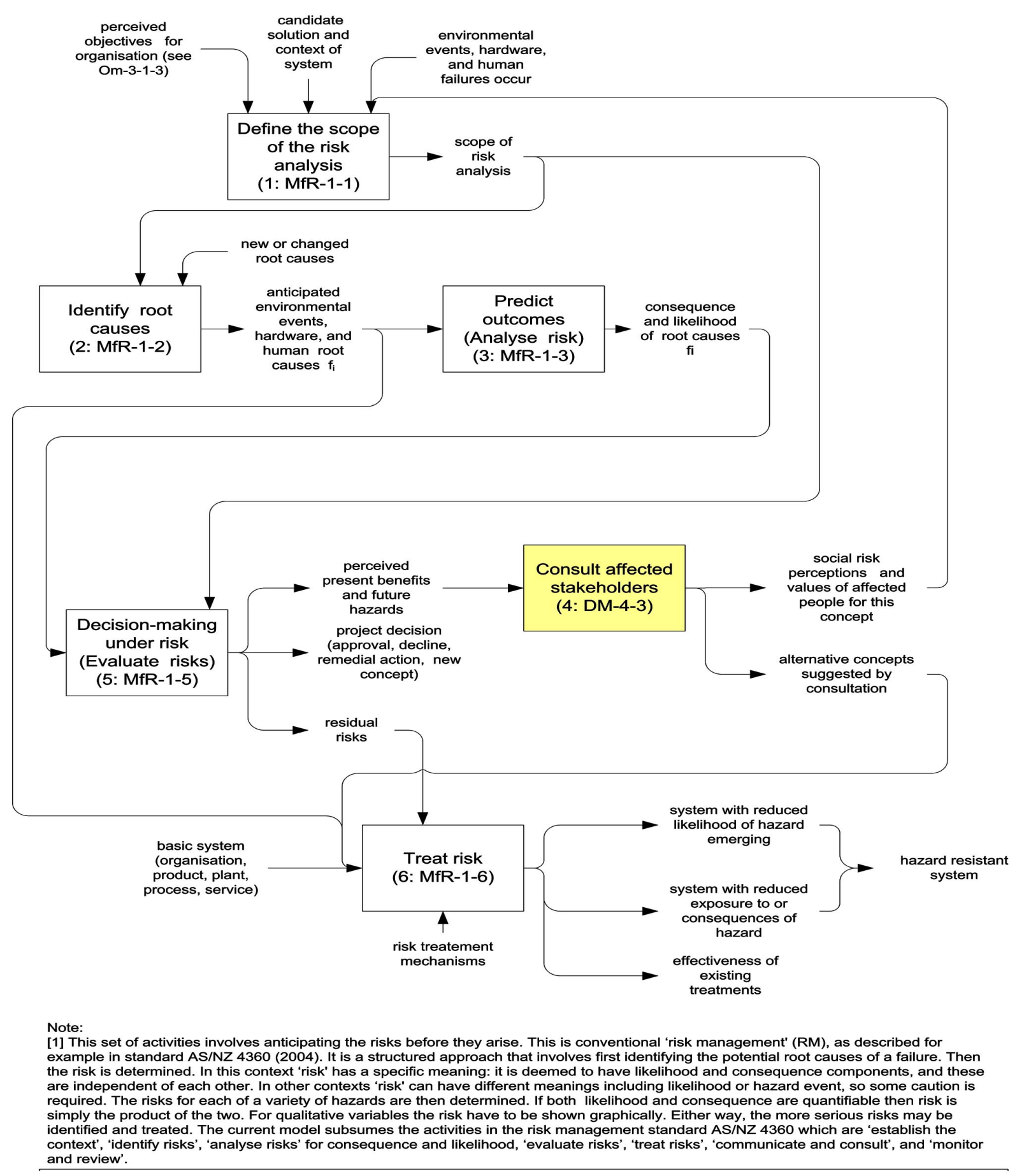

Fig. (1). Prophylactic risk management (MfR-1). 


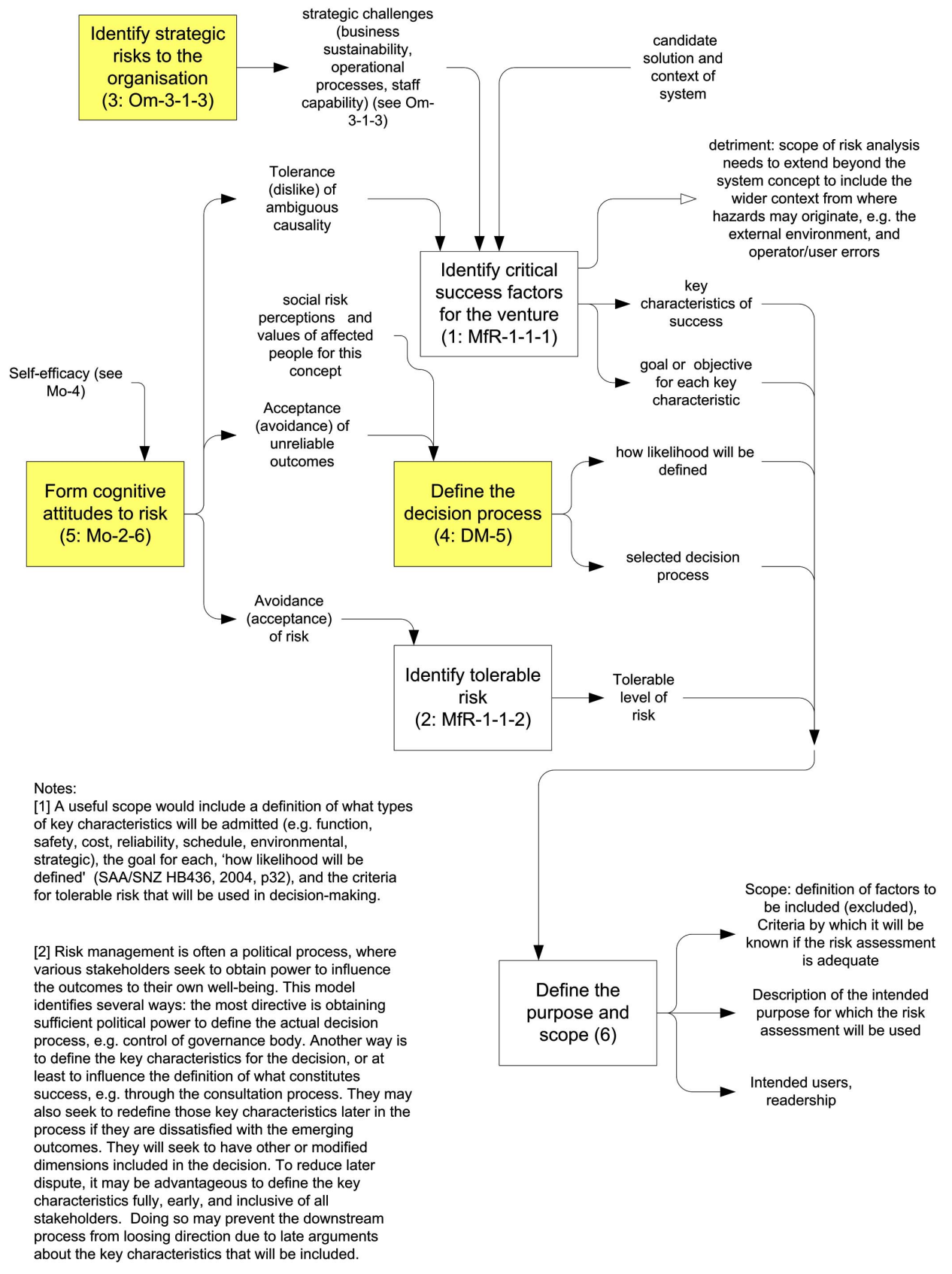

Fig. (2). Define the scope of the risk analysis (MfR-1-1).

vidual cognitive attitudes to risk (5). Both these are described in separate models, not detailed here.

The third behavioural effect is definition of the decision process (4), which involves politics, i.e. obtaining the power to control others. Risk management is often a political process $[7,8]$, where various stakeholders seek to obtain power to influence the outcomes to their own well-being. One of the ways they do this is to define the key characteristics for the decision, or at least influence the definition. They may also seek to redefine those key characteristics later in the process if they are dissatisfied with the emerging outcomes. Furthermore, stakeholders are not limited to customers and organisational owners, because other affected people (e.g. trade partners) will also have expectations of the project that may need to be included. Ideally the decision process (4) and the tolerable risks will be agreed by all these stakeholders prior to the analysis, though in practice this is often difficult. A separate model explores these issues.

The standards are premised on the assumption that the scope for any risk assessment can be completely and rationally defined. Here a different idea is proposed, that definition to such levels of determinism is not always possible, in which case the scope might at least describe the factors to be included (excluded), criteria by which it will be known if the risk assessment itself is adequate, and a description of the intended purpose for which the risk assessment will be used and who the audience will be (6). Thus the scope extends beyond the immediate concept of the technical system to include the wider context from where hazards may originate. There is a risk of unintentionally restricting the scope and 
consequently failing to identify key hazards [2, p35]. This failing may arise if the scope is too focussed on the intrinsic system (e.g. the technical concept) and fails to include the wider context from where hazards may originate, e.g. the external environment, and operator/user errors. It is precisely in the area of strategic risk that the standards have the least to say, and that is the next part of the model.

\subsection{Identify Critical Success Factors for the Venture (MfR-1-1-1)}

A core part of the scope is identifying the critical success factors for the venture, e.g. the business unit or firm. Scope definition is highly context specific, i.e. depends on the organisation and the proposed project, and this makes it difficult to provide supporting tools.

Regarding who should be involved, one of the principles of ISO31000 is that of inclusivity: that the views of stakeholders should be considered when setting risk criteria (sec. $3 i$ and 5.3.2) and HB436 elaborates on who those might be (sec. 4.3).

Regarding how the scope (or context) might be determined, HB436 provides some limited material to guide the process: primarily SWOT analysis. Regarding what a scope statement might include, the risk-management perspective is that the scope includes a definition of what types of key characteristics will be admitted (e.g. function, safety, cost, reliability, schedule, environmental, strategic) [2], the goal for each, 'how likelihood will be defined' [2], and the criteria for tolerable risk that will be used in decision-making.

However the risk management standard does not have much to say about this would be achieved, especially not the strategic implentations. While it is a useful start to have a list of possible key characteristics, [2, Table 1], which have been represented in Fig. (3) MfR-1-1-1-3, the wider issue is applicability. In particular, how does a risk assessor identify which are relevant to a particular case?

A solution is offered in Fig. (4) MfR-1-1-1, which suggests that it may be helpful to first identify the purpose for the venture (1), next the dimensions in which success is desired (2) (see Fig. (3) for some ideas), and then the criteria (qualitative or quantitative) by which success will be judged. Thus the purpose for the firm shapes the types of success desired (e.g. not-for-profit and commercial ventures have different dimensions of success), and the characteristics of success. This is a process of aligning the product and production systems with the strategic objectives of the organisation. Thus the author is suggesting that risk assessment, when applied at strategic level, needs to accommodate the fundamental purpose of the venture.

A 'venture' could be a simple project, a whole organisation, or say a national manufacturing sector. Risk management is only one part of the venture, and in the end there will be the production of a product/service (4). Thus, when risk management is being applied at organisational level the issues become strategic rather than technical, and the risk standards are not strong at this. It becomes necessary for the risk assessment to also include the preservation of factors that currently enable success (7), and identify the destabilis- ing strategic challenges (business sustainability, operational processes, staff capability) (8).

\subsection{Identify Strategic Risks to the Organisation (Om-3-1- 3)}

In the present context strategy is the proactive response to change. This includes the anticipation of uncertain future events, development of an envisaged future state of the organisation, and the activity of motivating others and equipping the organisation for that future. (Here organisation may refer to a work group, business unit, firm, industry sector, or state).

A related model exists for the process of setting strategy. Part of that model is relevant at this point as shown in Fig. (5) Om-3-1-3. Strategy setting is a complex process without a strong underpinning theoretical foundation and while there are some tools such as SWOT and PEST (see below), the overall process tends to be situationally specific and subjectively dependent on the personalities of the leaders involved. A slightly more structured approach is provided by the Baldrige framework [4], and the present model is broadly consistent with that, though the representations are different.

The main activities in the present model, not necessarily in the order in which they would be done since they could be overlapping, are as follows. There are activities to anticipate future changes in environment or technology (1), identify regulatory (2) and market (3) constraints, identify the life cycle of the product (5) (e.g. proximity to obsolescence and opportunities for refreshed or derivative products), and identify capability risks internal to the organisation (6). These are inputs to the activity of identifying the risks (threats and opportunities) to the organisation (4). The diagram contains other information, including identification of the objects involved, which space prevents being elaborated here. However attention is drawn to the opportunities (threats) present in various places in the diagram, these being: new product category born (dies); law change; staff capability. This is not an exhaustive list but simply illustrates the fact that risks present as both threats and opportunities, and not always in the most obvious ways.

The other important detail in the diagram is the identification of the mechanisms available to support the strategy process. These are SWOT analysis (internal strengths and weaknesses, external opportunities and threats), and PEST analysis (Political, Economic, Social, Technological, sometimes also Ethics and Demographics).

\subsection{Identify Tolerable Risk (MfR-1-1-2)}

The tolerable risk determines people's perceptions of acceptability of various degrees of risk. The model for this is shown in Fig. (6) MfR-1-1-2. It is proposed that tolerable risk is generally set implicitly (2) based on individual subconscious risk preferences (1), perceptions of the competence of subordinates (3), and organisational risk appetite set through the governance function (5). The model links through to other models on governance and cognition, but these are not elaborated here.

The textbook type process is that risk preferences should be determined explicitly before decision-making occurs. Perhaps this might be ideal, but the present model suggests 

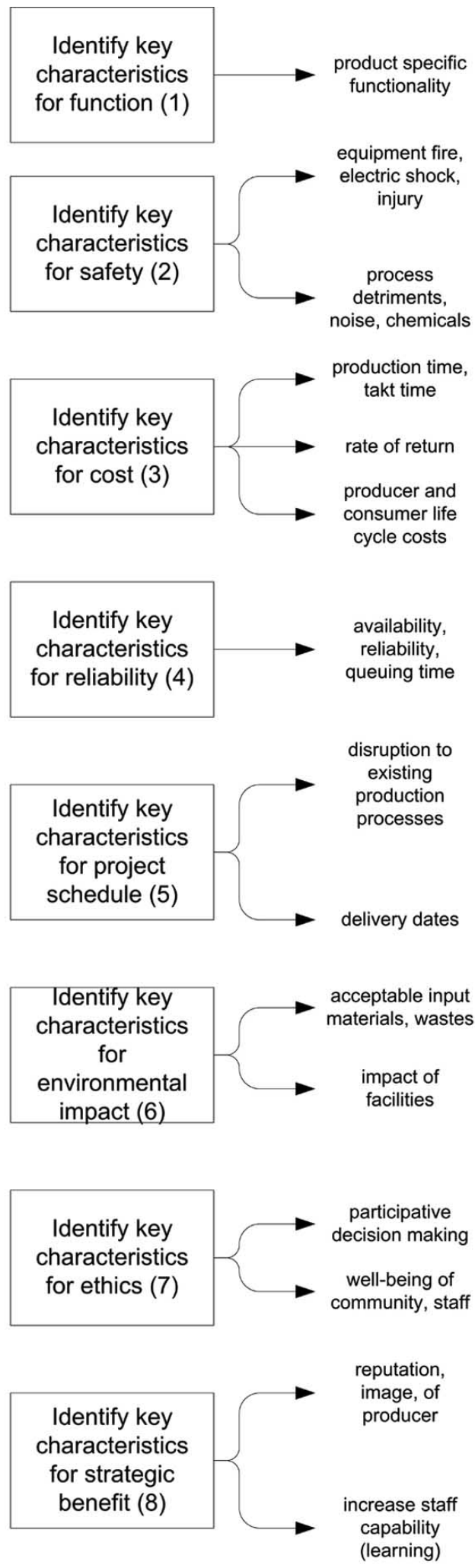

\section{Identify other key characteristics \\ (9)}

Fig. (3). Identify key characteristics of success (MfR-1-1-1-3).

Notes

[1] These key characteristics will vary for different projects, and only a sample are shown here for a generic project. They are based on the Key Elements of SAA/SNZ HB436 (2004).

[2] The key characteristics form the basis for subsequent evaluation of the risk, i.e. they become dimensions in the risk management decisions. Thus they appear in the downstream risk matrix (see MfR-1-3-6-2).

[3] Risk management is often a political process, where various stakeholders seek to obtain power to influence the outcomes to their own well-being. One of the ways they do this is to define the key characteristics for the decision, or at least to influence the definition. They may also seek to redefine those key

characteristics deeper into the process if they are dissatisfied with the emerging outcomes. They will seek to have other or modified dimensions included in the decision. To reduce later dispute, it is advantageous to define the key characteristics fully, early, and inclusive of all stakeholders. Doing so may prevent the downstream process from loosing direction due to late arguments about the key characteristics that will be included. 


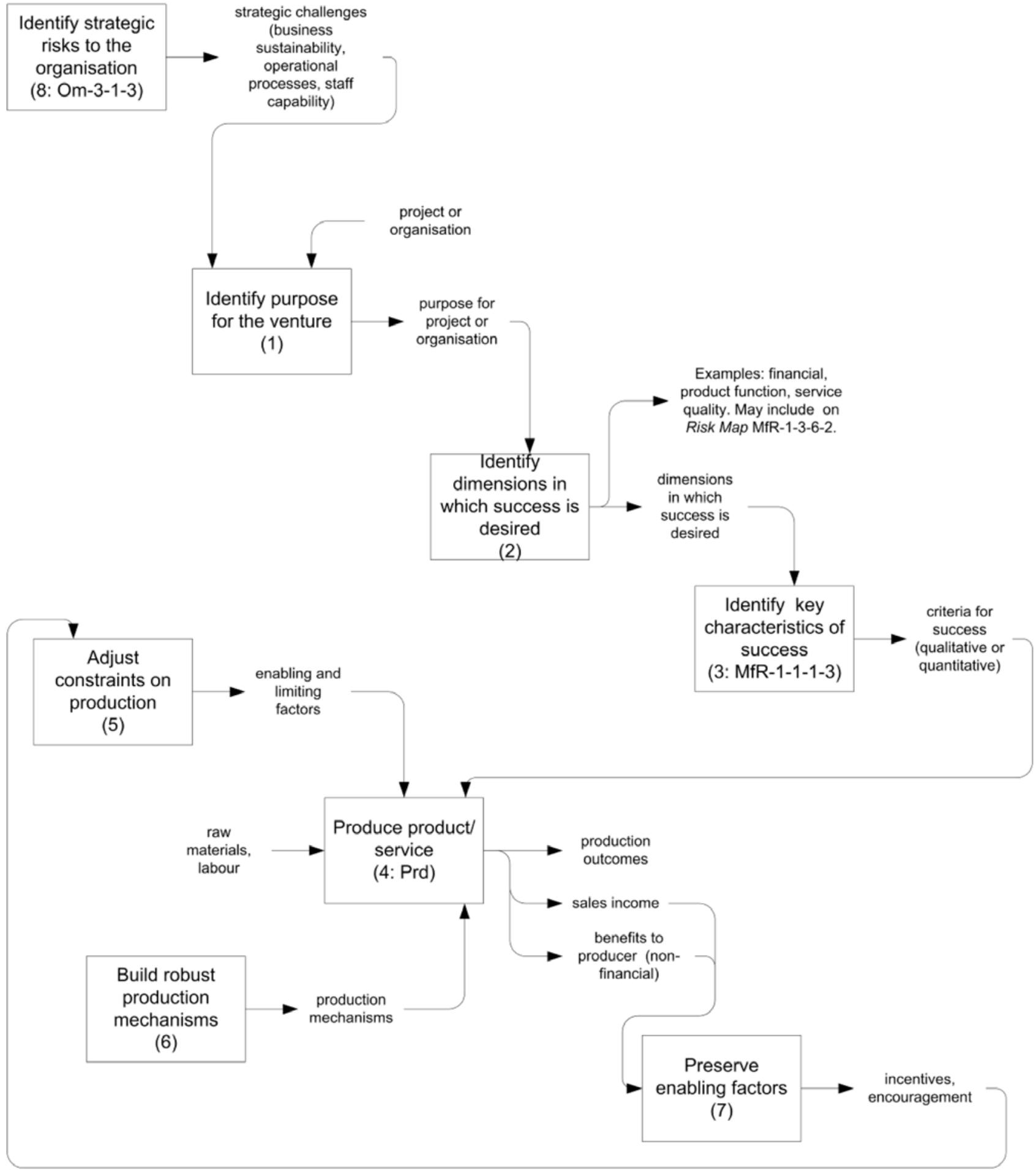

Notes:

A core part defining the scope is identifying the critical success factors for the venture. At the strategic level the 'venture' is the organisation itself. The risk management standard and literature does not have much to say about this would be achieved, so the author suggests the process shown here. The purpose for the firm shapes the types of success desired (e.g. not-for-profit and commercial ventures have different dimensions of success), and the characteristics of success. This is a process of aligning the product and production systems with the strategic objectives of the organisation.

Fig. (4). Identify critical success factors for the venture (MfR-1-1-1). 


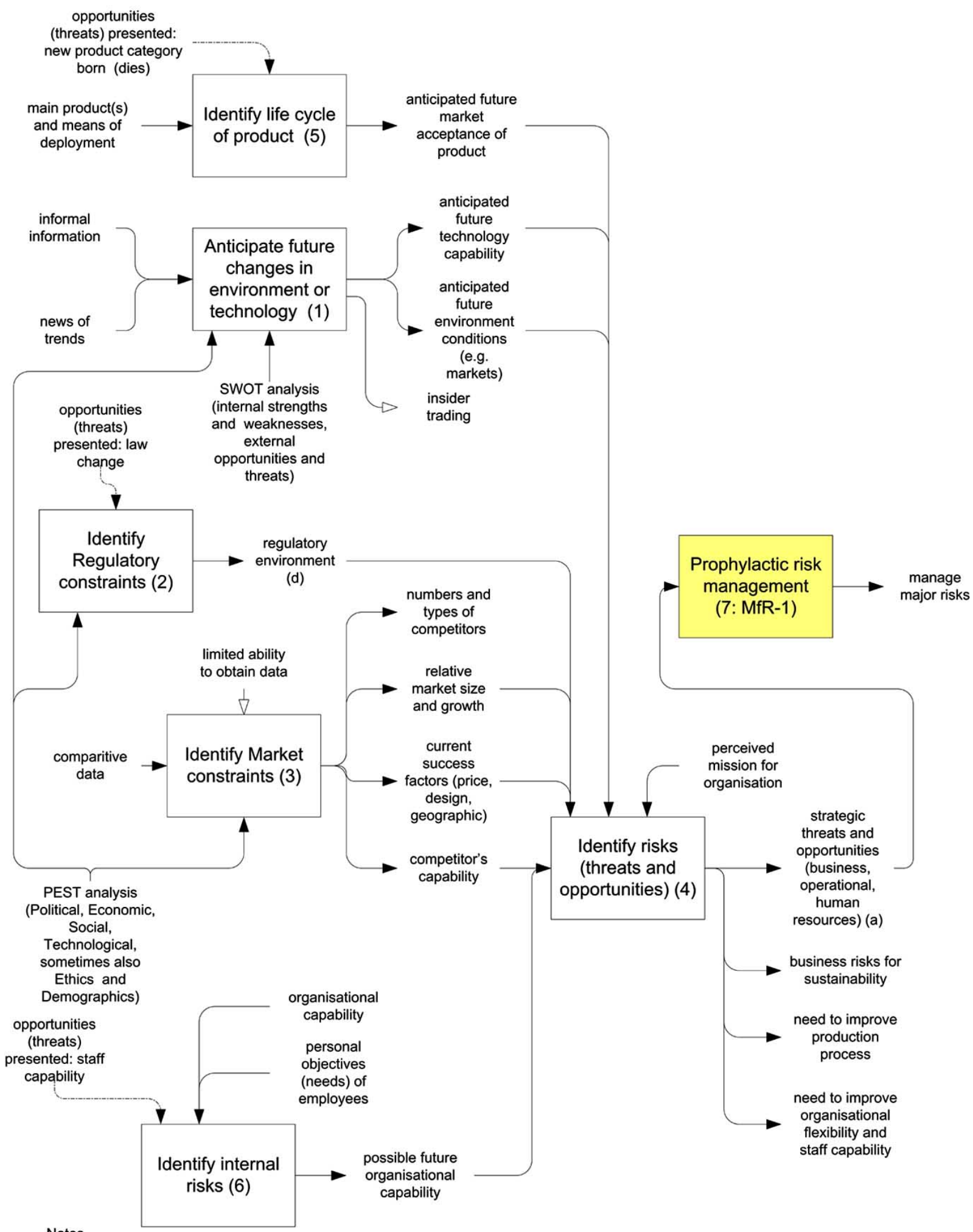

Notes

(a) 'Strategic Challenges The term "strategic challenges" refers to those pressures that exert a decisive influence on an organization's likelihood of future success. These challenges frequently are driven by an organization's future competitive position relative to other providers of similar products or services. While not exclusively so, strategic challenges generally are externally driven. However, in responding to externally driven strategic challenges, an organization may face internal strategic challenges. External strategic challenges may relate to customer or market needs or expectations; product, service, or technological changes; or financial, societal, and other risks. Internal strategic challenges may relate to an organization's capabilities or its human and other resources' (NIST, 2005).

(d) Includes health\& safety, accreditation, industry standards, regulations (financial, environmental, product).

Fig. (5). Identify strategic risks to the organization (Om-3-1-3). 
that the process is instead implicit and subconscious. Consequently, people are likely to be still ambiguous about tolerable risk late into the decision-making process. When risk may be quantified (e.g. financial value), then it is perhaps more possible to be explicit about risk tolerance, and earlier. However, strategic risks tend to be qualitative, and therefore other methods are necessary for representing the risk tolerance.

The ISO31000 approach to risk management calls for its application at all levels of the organisation. However it does not specifically identify the different levels of decisionmaking (and hence varying risk-tolerance) that may occur in an organisational context. It tacitly assumes that risk management is conducted by a single knowledgeable expert, or at least that there is homogeneity of risk tolerances, and that risk tolerances can be explicitly set beforehand.

In the present model it is suggested that strategic risk tolerance follow the naturally occurring delegation of decisionmaking within the organisation. Everyone inside an organisation knows what problems do and don't need to be escalated to superiors, this being part of the organisational culture. In more formal organisations this occurs through explicit delegation of authority. In many others the knowledge may be tacit, but it is real nonetheless. Thus a pragmatic way of extracting risk tolerances from an organisation may be to transform it to the dimension of corporate authority and ask 'Who should be informed?' This is illustrated within Fig. (6) MfR-1-1-2, where four levels have been assumed: Directors, Top management, Immediate supervisor, and Work team. Thus a negligible risk loss or gain would, by this table of risk tolerance, be managed at the workgroup level (empowerment) with routine procedures and general monitoring. At the other extreme, high risk loss or opportunity would involve the directors and executives deliberately considering the issue and making novel plans to avoid (capture) the risk. The diagram captures this graded response possibility.

This table of risk tolerances is flexible. It can be adapted to different organisational circumstances. It is particularly intended to assist with qualitative risk assessment in the organisational situation, such as arises for strategic risk management. It also circumvents the problem whereby individuals find it difficult to articulate their risk tolerances because they are subconsciously held.

\section{APPLICATION TO CASE STUDY}

A conceptual model has been shown for strategic risk management. However the model is at a relatively high level of abstraction and this section describes its application to a specific case study, this being a specific manufacturing organisation in New Zealand (NZ).

\subsection{Context of Manufacturing in New Zealand}

Manufacturing is important to New Zealand as it represents ' $15 \%$ of GDP, $63 \%$ of exported goods, and $14 \%$ of the total workforce' [9]. However, the globalisation of manufacturing has severe risks for countries like NZ with its higher production costs, small domestic markets, and geographically stretched supply and distribution chains. Nor is manufacturing always immediately associated internationally with $\mathrm{NZ}$, which is better known for its scenery and tourism. In- deed even within NZ manufacturing is somewhat obscure and media coverage and political commentary are often dismissive of the future of manufacturing [10]. Also, there has indeed been some long-term regional decline in manufacturing jobs [11].

Manufacturing industries therefore have significant economic risks in NZ. Furthermore, NZ businesses are small: '96\% employ fewer than 20 people' [12]. Consequently there is the danger that they may not have the people or financial resources to respond fully to risks, whether those be opportunities or threats. Thus, the risk is of losing the ability to create high-value exports, [10], and thus they might contract rather than thrive.

This section explores the problem, using the strategic risk management methodology developed above. The questions that need to be explored are: 'what are the risks, both the threats and the opportunities?', and 'how can these most effectively and efficiently be treated/captured?'

\subsection{Critical Success Factors}

The specific case under examination is a medium sized manufacturing firm in New Zealand; see Appendix A for company profile. Applying Fig. (2) MfR-1-1-1 to the firm under examination, the following observations were made:

- Identify purpose for the venture (firm) (1)

The firm advertises itself as innovative, and perceives itself as primarily a design and production organisation.

- $\quad$ Identify dimensions in which success is desired (2)

Concepts of quality and reliability feature strongly in its literature. Financial viability is an implied requirement.

- $\quad$ Identify key characteristics of success (3)

In general, the criteria for success for a manufacturing firm are customer satisfaction (quality), high reliability (low warranty claims), robust cash-flow and dividends to owners.

- $\quad$ Produce product/service (4)

The dominant commercial output from the firm is physical product.

- $\quad$ Adjust constraints on production (5)

This aspect could not be determined in the present analysis which focuses on the big picture. However a brief description of the concept may be useful for practitioners who wish to apply it to this level of detail. The concept is that an important function of executives is to set the enabling and limiting factors on the production of the organisation (production can include products as well as services and other less tangible outcomes). The limiting factors prevent the business production processes from straying into error, and may use quality control methods to achieve this. However elimination of errors is insufficient on its own: there also need to be enabling factors, i.e. methods for initiating motivated behaviour of staff, and for creative innovation. Organisa 


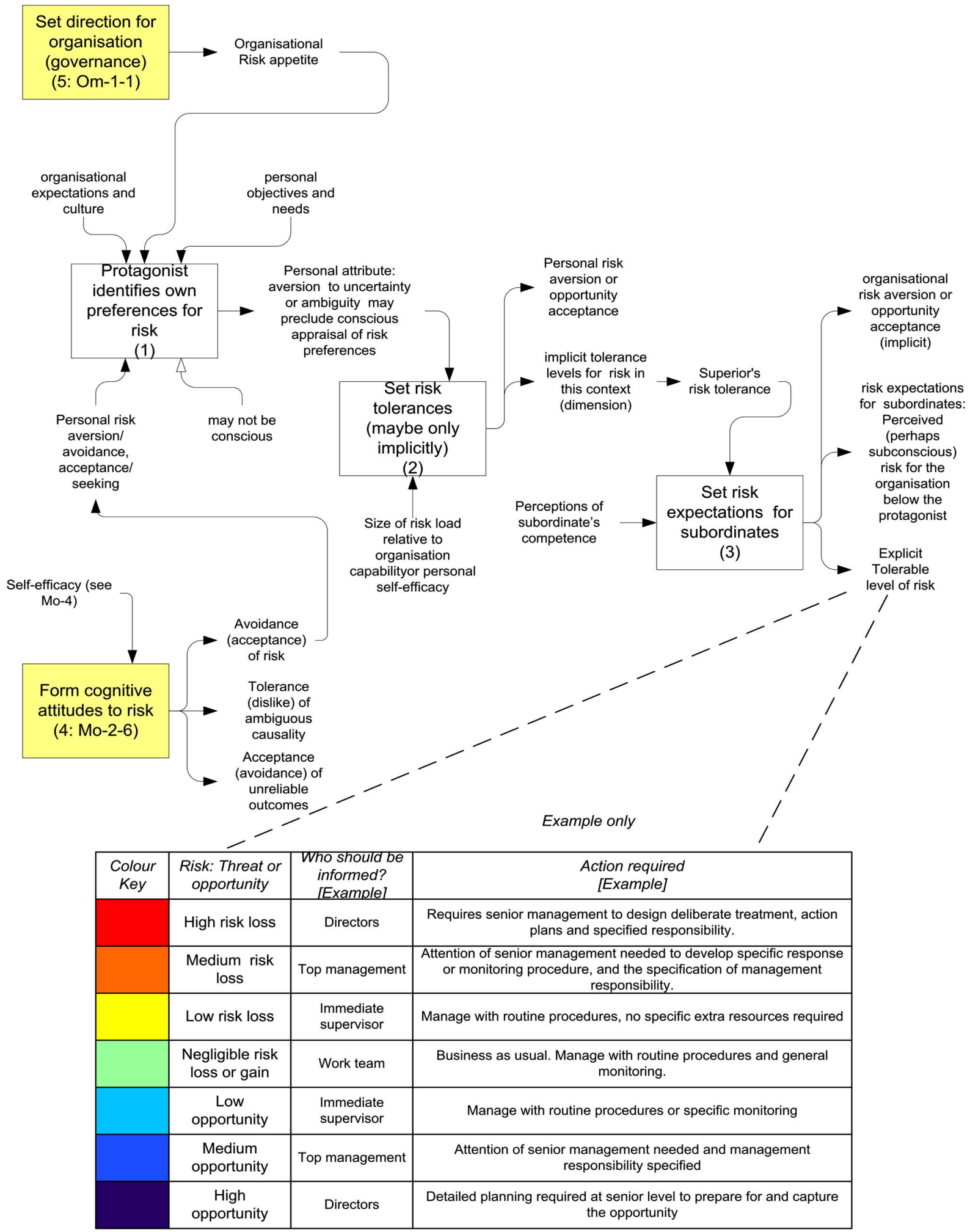

Fig. (6). Identify tolerable risk (MfR-1-1-2).

tions may struggle to find the balance between the enabling and the limiting factors. Some organisations emphasise the limiting factors because they are averse to failure, and tend to becoming bureauc- racies where there is a process for everything but also staff demotivation towards the organisational purpose and consequently stasis of the organisation. Other organisations emphasise the enabling factors 
by performance-based-pay and other extrinsic incentives, and risk immoral organisational behaviour along the way. The concept in this model is that the organisation will adjust the constraints on its production to avoid the worse errors and encourage behaviour that is appropriate with the organisational purpose and also socially acceptable (however it construes the latter). Mechanisms to achieve this include procedural controls, extrinsic incentives, and intrinsic motivators. This is a job for executives since (a) it concerns internal alignment of the organisations, business processes with its stated purpose, and (b) it is difficult to achieve since the organisational culture is often a restoring force.

\section{Build robust production mechanisms (6)}

This detail does not feature in the present analysis as the case study does not go to this level. However a brief description of the process follows. The basic principle is that the production mechanism needs to robustly deliver the venture outcomes. For example, 'robust' in the context of assembly of dishwashers refers to consistent quality of product and may prescribe quality controls to achieve this. However 'robust' as regards the process of designing the dishwashers refers to providing functions to satisfy the customer and different mechanisms would be used in comparison to the assembly case. Recall that 'production' here refers to any process for producing product or service, etc. and therefore corresponds to the business processes in general. Robust refers to the ability to tolerate perturbation, as opposed to a fragile system that only operates well under certain conditions and otherwise not. The production systems vary widely, being dependent on the nature of the business. For example, manufacturing organisations might use just-in-time (JIT) or other lean inventory strategies, and they may even tweak them to make them more robust (there are limitations with pure JIT that present as fragility under certain conditions). Whatever the production systems, they need to consistently produce quality products.

\section{Preserve enabling factors (7)}

This is another detailed component that was beyond the scope of the present analysis. The central idea is that no organisation stays totally in stasis or unchanging equilibrium with its environment; either the external or internal environment changes. External changes include competitors, legislation, customer preferences, technology, etc. Internal changes include staff-turnover, production system, new leadership, etc. The changes may be incremental or radical jumps. Thus the factors that might be making the organisation successful at the present may not persist into the future. It is therefore necessary to preserve those changing success-factors. For example, if an organisation relies on innovative, motivated and hard-working staff, how will it preserve that behaviour as a new generation of employees enter the organisation with different expectations of life and employment? Or, if organisational success is currently caused by customers perceiving the product to be of superior quality, how will that perception of quality be maintained when other competitors emerge offering higher quality or lower price (or both)? Leaders within the firm understand the factors that currently result in organisational success (see \#3) and (a) seek to preserve those factors while that is still appropriate, and (b) change them as necessary as the competitive environment changes.

\subsection{Risk Analysis}

The strategic risk analysis followed Fig. (5) OM-3-1-3. It was based on SWOT analysis, but categorised by PEST analysis. Each of the risks was assessed for consequence and likelihood, and the assessment placed in Table 1. As the case concerns strategic risks, the analysis has used qualitative rather than quantitative variables, as the latter can misrepresent the precision. The likelihood scale was 'almost certain, likely, possible, unlikely, rare, very rare, almost incredible'. The consequence scale was 'severe loss, major loss, moderate loss, minor loss, negligible loss, neutral, negligible gain, minor gain, moderate gain, major gain, huge gain'. Alternative scales are possible. Results are summarised in Table $\mathbf{1}$.

Column 1: The table is structured by PEST and the external/internal origin of the risk.

Column 2: The anticipated threats and opportunities are shown, based on SWOT analysis. The data are simply representative rather than complete.

Column 3-4: The likelihood (column 3) and consequence (column 4) were assessed.

Column 5: Overall assessed risk priority, refer next section.

\subsection{Risk Evaluation}

Risk tolerances were used as per the risk scale in Fig. (6) MfR-1-1-2. This assigns a description of the level of risk, ranging from 'high risk loss' to 'high opportunity'. This particular seven-point scale is the author's construction and was found to have sufficient resolution for the case under examination. Alternative scales are possible.

For convenience a colour was identified with each level of risk. The same colours were then assigned to the risk map (Fig. 7) MfR-1-3-6-2. Again this is a subjective process and can be expected to vary from case to case as it reflects situational and personal risk tolerances. Some firms will have an appetite for opportunity and the resources to survive if captured opportunities fail to be profitable, whereas other firms will seek to always play-it-safe. These thoughts will influence their risk tolerances and thus the assignment of risk colour to the risk map. The assignment used here is simply the author's suggestion as a starting point. Therefore firms that sought to replicate the study for their own situation could discuss the risk tolerances of decision-makers within the firm, and modify the risk scale and risk map accordingly.

The risks were then plotted by consequence and likelihood on the risk map, see Fig. (7) MfR-1-3-6-2. Internal risks are highlighted. For meaning of background shades please see the Risk Scale in Fig. (6). 
Table 1. Risk Register

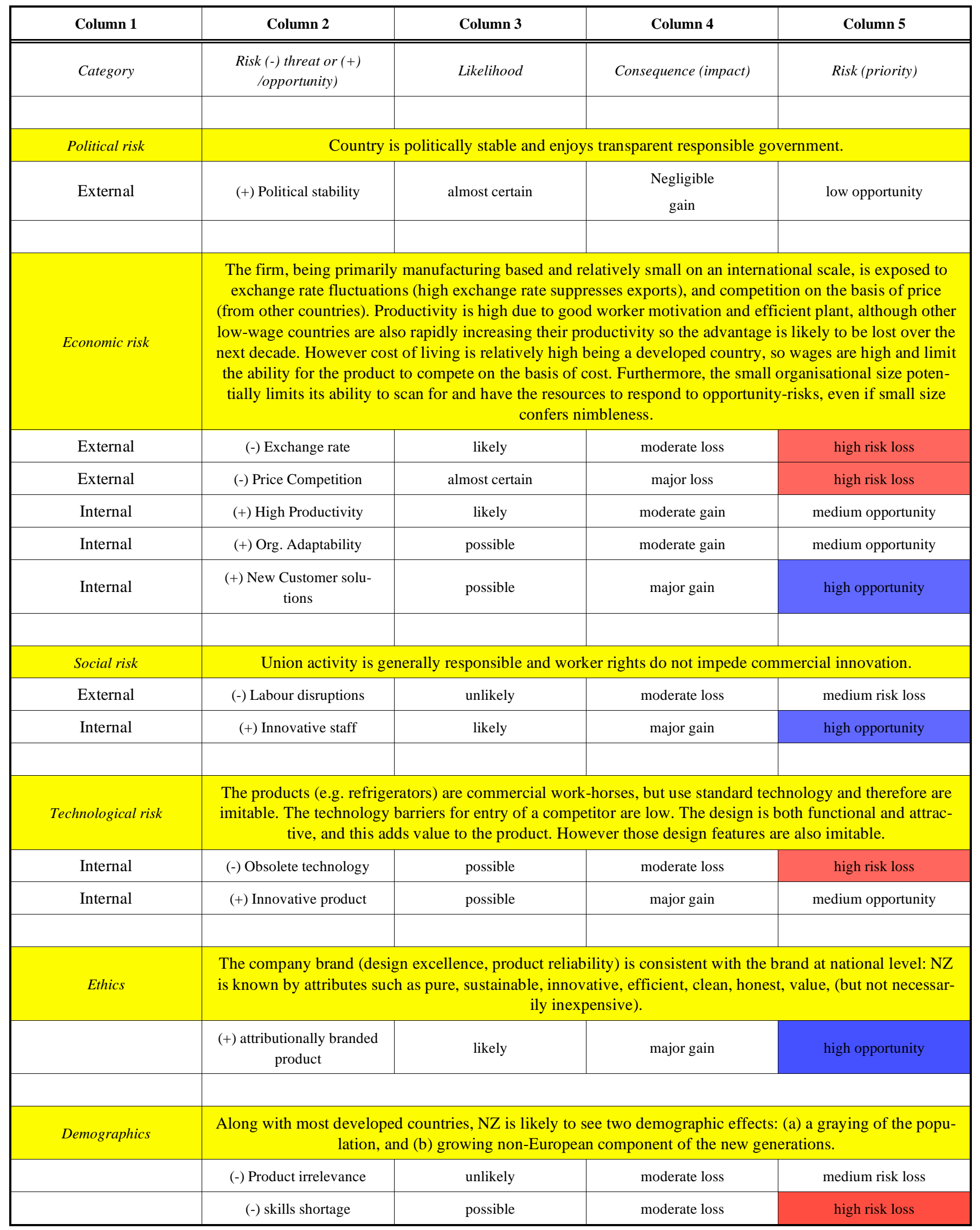




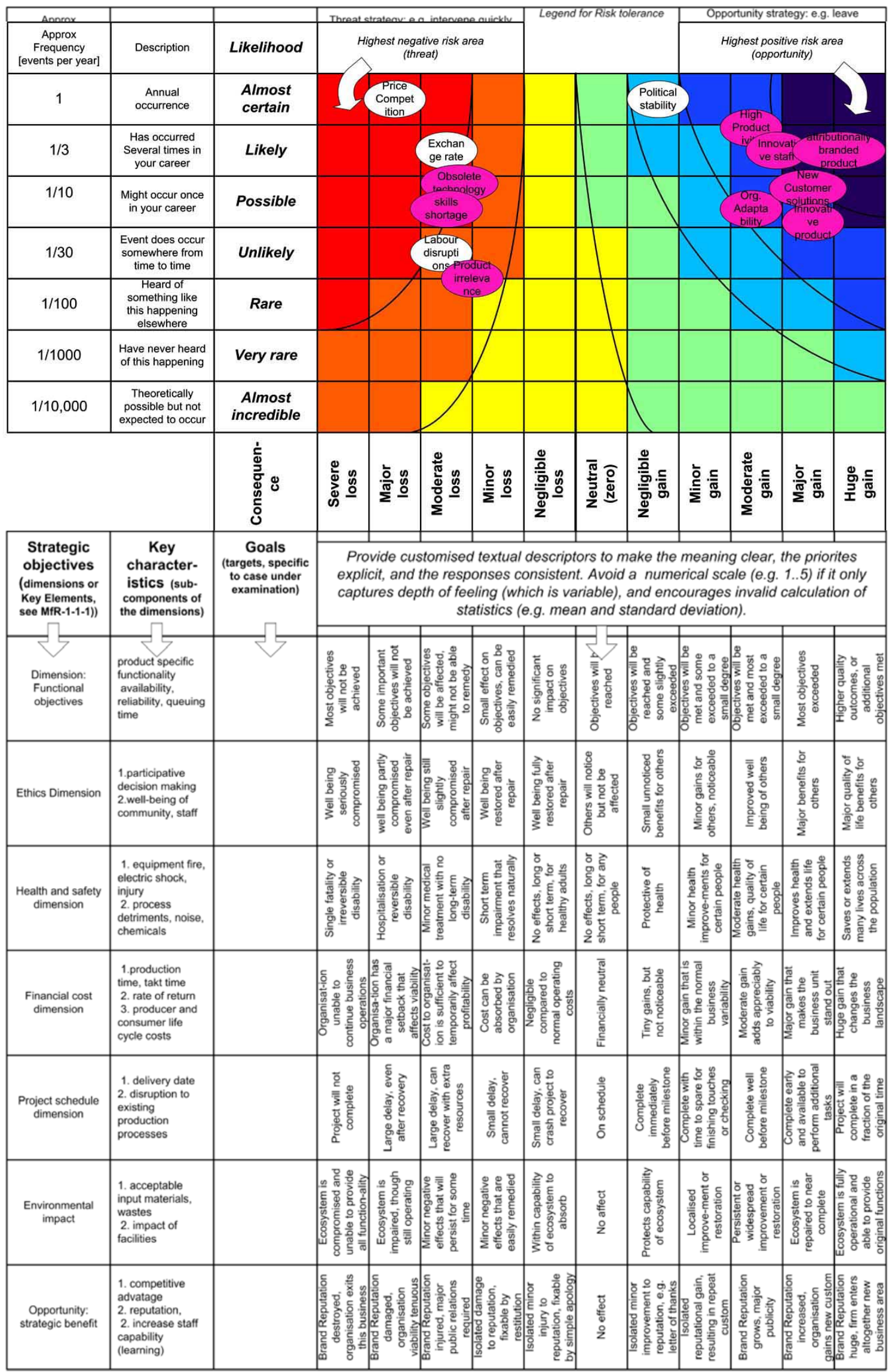

Fig. (7). Map likelihood vs consequence (MfR-1-3-6-2). 
The importance of each risk was then determined by the colour of region in which it lay on Fig. (7) MfR1-3-6-2. This allows the risks to be categorised according to the risk scale of Fig. (6). The resulting risk priority of each risk was inserted into Table 1 Column 5. This is important as it permits the risks to be (a) prioritised, and (b) allocated to different functional groups within the organisation. The usual process is that higher priority risks need some attention or treatment, whereas low priority risks can be handled as routine operations or ignored altogether. Organisations have scarce resources and in this way risk management helps focus on the issues that are worth solving.

The final result is that the analysis identifies several large threats and opportunities, and these are extracted to Table 2. Note that only the largest risks are included here.

Table 2. High Risk Losses and High Opportunities

\begin{tabular}{|c|c|}
\hline \multicolumn{2}{|c|}{ Risks } \\
\hline High risk losses & High Opportunities \\
\hline \hline Exchange rate & New Customer solutions \\
Price Competition & Innovative staff \\
Obsolete technology & Innovative product \\
Skills shortage & Attributionally branded product \\
\hline
\end{tabular}

\subsection{Treatment for Strategic Risks}

Some of the threats can be readily treated on their own. For example Exchange rate volatility may be covered by insurance or currency hedging if necessary, and the risk of obsolete technology countered by capital investment. In turn that might involve a second round of analysis, seeking ways to raise the necessary capital. Likewise the opportunities could be captured by individual projects. However, at a strategic level it makes more sense to take an integrative rather than piecemeal approach, and seek to design a single strategy that will treat as many threats and capture as many opportunities as possible, and then leave the residual components to be addressed by specific projects within the organisation. Possible strategic options for consideration:

\section{Scenario 1: Move Production Overseas}

This scenario is primarily a response to the threat of Price Competition. Many other manufacturers have taken this decision-path.

Benefits:

Moving manufacture to Asian countries with cheaper production costs, and retaining the design and corporate management locally, is a solution, though perhaps a short-term one. It is almost certain to be effective regarding production cost.

Detriments: However firms that have attempted it sometimes report ${ }^{1}$ that the geographic separation between design and manufacture means that less and less development

${ }^{1}$ Personal communication, Canterbury ICT Cluster meeting, 3 Oct 2007, held at Allied Telesis Labs, Christchurch. gets done locally, it being easier to get it done closer to the manufacturing plant. This is due to the intimate relationship between design and manufacture, especially regarding continuous quality improvement, e.g. reducing production waste and increasing efficiency. Furthermore, outsourcing of manufacturing may not capture all opportunities. It tends to involve large product volumes based on common hardware platforms or components, and thus it could be difficult to differentiate the product from other competitors or to produce low volumes of customised products. Thus this solution could preclude capture of opportunities like new customer-solutions. Furthermore, outsourcing manufacture to low-wage countries tacitly assumes that those countries will always remain lowwage, whereas it is more prudent to assume that their standard of living and hence labour costs will rise over time. It may be difficult for a firm to bring design and production back in-house when economic or strategic changes make that necessary, if the local human and technological capability has been lost. So outsourcing is not necessarily a stable long-term solution.

\section{Scenario 2: Move Into the High-Value Market}

This scenario is a response to the opportunities, and simultaneously seeks to treat the threat of Price Competition. The idea would be to (a) change the product portfolio to the high-value end of the market (through new product development, relinquishing products inconsistent with the brand, design excellence, reliable product, and marketing), (b) add value to the customer in other ways, especially service, (c) deliberately align the product/service with the NZ brand, i.e. producing attributionally branded product. This scenario presumes that product quality is essential, but the risk is that it may be no more than a hygiene factor (i.e. necessary but not sufficient for success) in the long-term, as 'manufacturing is no longer just about the physical product' [10]. Thus for a manufacturing organisation in a country like $\mathrm{NZ}$ where costs are relatively higher than in Asia, success may not be so much production of boxes of product but providing customer solutions through the product and associated services. This would seem to require an intimacy with the customer, and perhaps a change in focus within the firm. To achieve this would require staff capability for innovation.

Benefits: $\quad$ Long-term organisational viability. Ability to respond to new opportunities in the market due to retention of design and production (plus their co-location). Moving away from competing on the basis of cost reduces the exposure to exchange rate fluctuations, since the product/service is purchased by on the basis of the customer's perceptions of intrinsic value rather than primarily cost. This decision-path is en- 
couraged by the NZ state (through NZTE), so support may be available.

Detriments: Transition to this mode of organisational operation would require leadership, commitment of staff, possible organisational cultural change (new values and attitudes of staff and the labour force, including employment conditions), and sufficient resources. It is a longer-term solution and may be difficult to deploy if short-term cash-flow is the reason the firm exists. There is no guarantee of success.

These are simply two of many possible solutions. They illustrate the complex choices facing the sector. It also illustrates the possibility of integrating scenario planning with strategic risk management. The purpose of scenario planning is to present possibilities for the future, perhaps even uncomfortable discontinuous change, so that participants can be cognitively challenged early enough to effectively plan for the risks. By presenting the above scenarios it is not suggested that the firm has to follow only one of these; instead the scenarios depict the extremes of the solution space. They are intended as points of departure for solutions that may (or not) include elements of these scenarios.

\section{DISCUSSION}

\section{Outcomes}

Several outcomes have been achieved here. The first is a methodological contribution, whereby a conceptual model has been described for strategic risk management. This provides a candidate theoretical foundation for the topic. Important characteristics of this model are its integration of strategic planning with risk management, hence strategic risk management (SRM). This has not previously been demonstrated, at least not in the structured manner shown here.

The second contribution is an analysis of the strategic implications for the manufacturing sector, specifically a case study of a firm in the NZ context. Strategic management of manufacturing is otherwise somewhat ad-hoc and poorly integrated with risk management, and the model provides a method that could help organisations navigate the economic turbulence of the global manufacturing sector.

\section{Limitations}

It is important to realise that the process of creating the conceptual model involved successive refinement, even redefinition, of the model to explain the observed real system behaviour. There was an inductive reconciliation with existing knowledge about the process being analysed. This, plus the structural consistency checking of the IDEF0 process, reduces the chances of the model being in error. However those chances cannot be eliminated altogether. Like any system model, it is dependent on the on the perspective taken by its architect and the modelling notion, and is therefore subjective.

No claim is being made that this is the only solution either: it is expected that there could be many valid models of the process depending on the perspective taken and the modelling notion used. For all these reasons, the author rec- ommends that the conceptual model presented here be considered conjectural: a subjective theory that is not obviously invalid, has some practical usability, but which cannot be considered proven or validated.

\section{Implications for Practitioners in Manufacturing Firms}

This analysis has been conducted at an overall strategic level. It shows that decisions regarding manufacturing are complex, and depend on situational factors, particularly what decision-makers (e.g. executives and directors) perceive as the purpose for the firm and the criteria of success. If the corporate mind-set, whether consciously or not, is dominated by short-term financial gain or competition on the basis of cost, then decision-making is anticipated to favour defensive strategies like outsourcing production to low-cost countries.

However, the analysis also shows that such strategies may miss some significant longer-term opportunities. These include expanding the offer-of-value made to the customer through heightened understanding of customer needs and the embodiment of that knowledge in better product design, provision of related products, and provision of relevant service. Some of these opportunities, particularly the opportunity to branch into service-provision, are not excluded by outsourcing production. However, several of the design related opportunities are excluded, and may be difficult for a firm to recapture later. Thus an alternative solution is proposed whereby the manufacturer would concentrate on the high-value end of the market (through design excellence, reliable product, and marketing), add service and other value to the customer, and produce attributionally branded product.

The work presented here has been conceptual and representative, and to clarify the decision for a particular firm it would be necessary to analyse the risks in further detail. Subsequent project phases could examine the issues to finer resolution and greater accuracy, and implement change, and Appendix B suggests how this might be achieved.

\section{Implications for Risk Management Practitioners in General}

A method has been demonstrated for strategic risk management. Tools for planning strategy, (e.g. SWOT, PEST) have been integrated with risk management. The method specifically addresses the organisational context. For example a method is provided to align risk tolerances to organisational decision-making, from governance, management, through to autonomous workgroups. On the treatment side, scenario planning has also been integrated. The overall result is an integrative methodology for strategic risk management that has demonstrable usefulness in the manufacturing sector and the potential to be applied to many other strategic settings.

\section{Implications for Further Research}

This paper has shown how risk management is connected to other organisational activities. This is a somewhat atypical direction for risk management, which otherwise tends to emphasise the technological risks or operator errors. A methodology has been demonstrated whereby risk management may be integrated with other areas, in this case strategic planning. More work of the validation type is required 
to move the model from a conjecture to an established theory. Other work might develop additional tools for strategic risk management, or extend the integration to other areas such as change management.

\section{CONCLUSIONS}

The paper makes a methodological contribution in several ways. First, rather than concentrate on just the threats it identifies the opportunities and specific mechanisms by which they might be captured. This is somewhat novel in that the risk assessment method $[1,2]$ provides little if any guidance on methods for identifying opportunities. Opportunities are indeed acknowledged by those methods but the tools they provide are mostly focussed on identification and elimination of threats. Throughout the literature the tools for dealing with threats predominate over tools for opportunity. The paper shows how practitioners may more deliberately include opportunities in the risk assessment process.

The paper makes another contribution by developing a theoretical model for intersecting risk management with strategy formulation, in 'strategic risk management'. Such an intersection is not precluded by the existing risk management literature, but is only partially developed. Risk assessment is often premised on a clean rational process, with quantification of the variables being perceived as the ideal. However, at the strategic level the process is more complex as the variables cannot always be quantified with any confidence, and the knowledge of how those variables interact is often subjective rather than mathematical, i.e. high epistemic uncertainty. This paper contributes by showing how strategic considerations may be used in the risk identification and treatment processes. It also shows how the perceptions of decision-makers (e.g. executives and directors) as to the purpose for the firm may affect the criteria of success, their perceptions of threat and opportunity, and ultimately their strategic responses.

A third contribution is in the way the paper specifically addresses the risks faced by a manufacturing organisation. Within the limitations of the data available for this analysis, the results suggest that a strategy of outsourcing production to a lower wage country is not the only possible solution for a product-manufacturing firm. It may not be the best for the longer term, precisely because it is a defensive strategy and therefore precludes capture of certain other opportunities.

The fourth contribution is the provision not only of a theory, but also an integrated set of methods for use by practitioners. These methods are not prescriptive, but instead offer suggestions that can be adapted to various situations. A suggested project plan for deployment is also provided. While the methodology has been illustrated by application to the strategic risk in manufacturing organisations, it has the potential to be used in other situations in response to threats and opportunities that affect the long-term financial viability of the organisation.

\section{A. APPENDIX: COMPANY PROFILE}

The firm under examination was selected as being representative of many NZ industries. It manufactures refrigeration and heating products for the light commercial market.
For example, the refrigeration products include storage and display cabinets for supermarkets, restaurants, and food \& beverage processing industries, and the heating products include industrial workspace space heaters. Most of the products are provided in standard configurations, although the firm will also produce custom-built units. The firm has its own research \& development, design, manufacturing, and marketing capabilities. It is based in New Zealand and Australia, where most of the customers are located. The distribution chain is primarily through wholesale to other vendors and the building industry, and it has few if any direct outlets to the public. It is a privately owned firm, and employs several hundred staff. The company's core values include product features (durability, reliability, safety, etc.), and technological innovation. The firm projects itself as primarily a design and production organisation, being proud of its capabilities in design, production capability, and quality accreditation.

Looking at the overall exports from NZ one can see that the products of this company would, fit into the category 'Electrical machinery and equipment' which is one of the larger export categories. Furthermore, the refrigeration products are important in supporting the food-processing parts of the economy. Consequently the firm has a significant market in both direct and indirect contribution to exports.

As regards NZ exported goods, the main commodities in 2006 in rank order of value \$(million) were: Milk powder, butter and cheese 5,762; Meat and edible offal 4,500; Logs, wood and wood articles 1,960; Mechanical machinery and equipment 1,791; Aluminium and aluminium articles 1,261; Fruit 1,161; Fish, crustaceans and molluscs 1,146; Electrical machinery and equipment 1,045; Iron and steel and articles 729; Wool 689; All merchandise exports 32,430 [12].

\section{B. APPENDIX: TERMS OF REFERENCE FOR FUR- THER ANALYSIS}

The analysis presented here is simply a start, and only the high-level strategic issues are included. Furthermore, it is based on representative information about the organisation under examination, so in applying the method to other firms the appropriate details would need to be included. Further analysis would have the following objectives:

Project scope: Perform a risk assessment within the firm.

Deliverables: Risk management documents including risk assessment, project plan for deployment.

Objectives for the risk management team: Identify risks, both threats and opportunities, determine likelihood and consequence for each, assist executives identify their own risk tolerances by which the risks may be ranked by importance, provide evidence on which executives may make rational strategic decisions, and assist executives in the management of risks within the organisation as the strategic decisions are implemented.

Knowledge and competencies required of risk team: Understanding of risk management practices, project management knowledge or experience, organisational experience, sensitivity to customer needs. 


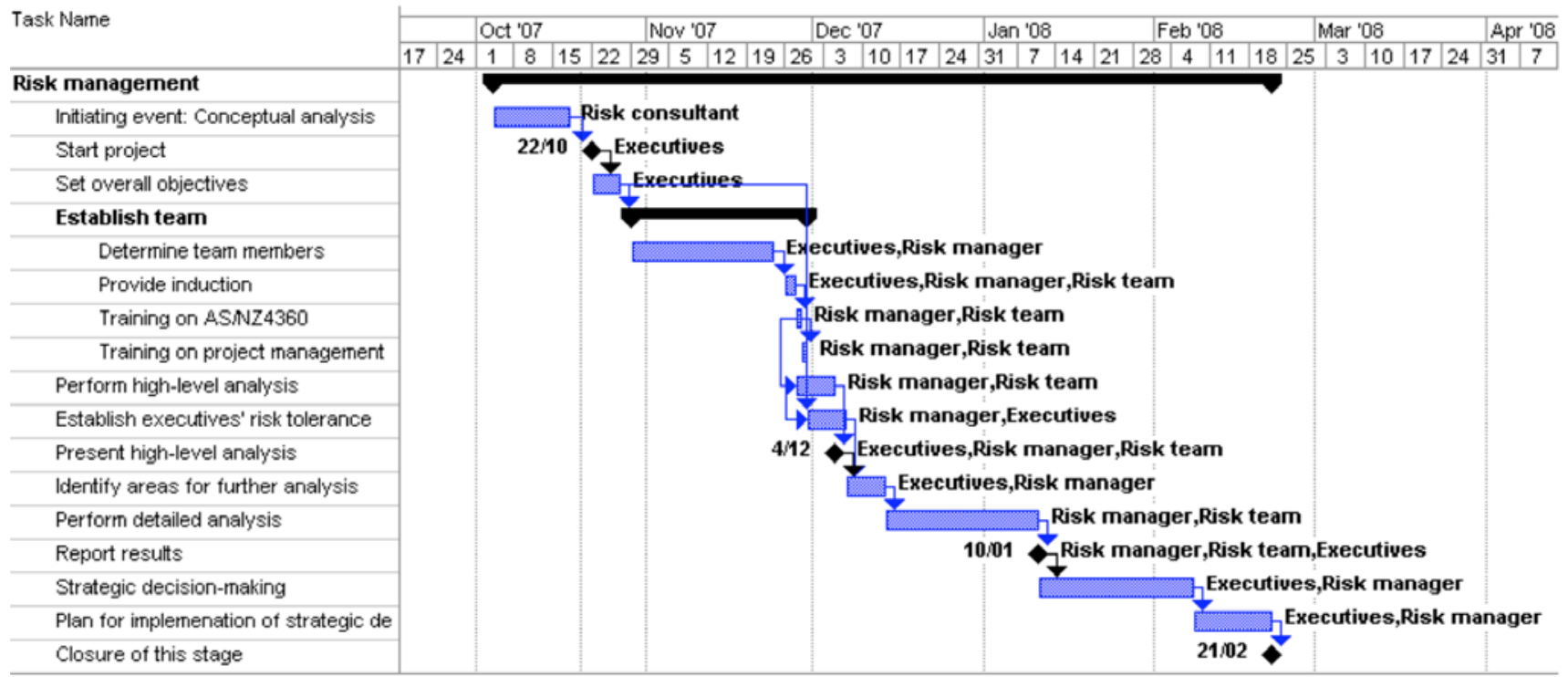

Fig. (B1). Project plan for first stage of the project from initiation through detailed risk assessment, and stopping after the plan for the subsequent stage is complete. The content of that subsequent stage cannot be anticipated at this time as it depends on the decisions made during the first stage.

Project plan: The possible distribution of work and the project schedule for a first stage of a more detailed risk management project are shown in Fig. (B1).

\section{REFERENCES}

[1] AS/NZS 4360, Risk Management. 2004, Australian/New Zealand Standard, Standards Australia, GPO Box 5420, Sydney, NSW 2001.

[2] SAA/SNZ HB436, Risk Management Guidelines. 2004, Australian/New Zealand Standard, Standards Australia, GPO Box 5420, Sydney, NSW 2001.

[3] ISO 31000, Risk Management - Principles and Guidelines, International Organization for Standardization, 2009.

[4] NIST. 2009-2010 Criteria for Performance Excellence, Baldrige national Quality Progam. 200924 Sept 2009]; Available from: http://www.baldrige.nist.gov/PDF_files/2009_2010_Business_Non profit_Criteria.pdf

[5] FIPS. Integration Definition for Function Modeling (IDEFO). 1993 12 Aug 2003]; Available from: http://www.itl.nist.gov/fipspubs/ idef02.doc
[6] KBSI. IDEFO Overview. 200012 Aug 2003]; Available from: http://www.idef.com/idef0.html

[7] S. Jasanoff, The political science of risk perception. Reliability Engineering \& System Safety, vol. 59, no. 1, pp. 91-99, 1998.

[8] P, Slovic, The risk game. Reliability Engineering \& System Safety, vol. 59, no. 1, pp. 73-77, 1998.

[9] NZTE. Manufacturers Have Their Say on Industry Vision. 2006; Available from: http://www.nzte.govt.nz/section/11894/15213. aspx

[10. NZTE, Manufacturing +: A Vision for World Leading New Zealand manufacturers. New Zealand Trade \& Enterprise, 2006.

[11] CMA. Are We Going to be Working Longer, Not Smarter in the Future? 20072 October 2007]; Available from: http://www.cma.org.nz/index.cfm/media_releases/070807_employ ment.html

[12] Statistics NZ. New Zealand in Profile: An Overview of New Zealand's People, Economy and Environment. 20072 Oct 2007]; Available from: http://www.stats.govt.nz/NR/rdonlyres/5AE857F5 8ED6-4A98-BDE9-5EFA9C5D4EAD/0/5598NZinprofile2007ffW EB.pdf

(C) D.J. Pons; Licensee Bentham Open.

This is an open access article licensed under the terms of the Creative Commons Attribution Non-Commercial License (http://creativecommons.org/licenses/by-nc/3.0/) which permits unrestricted, non-commercial use, distribution and reproduction in any medium, provided the work is properly cited. 